\title{
Causes of female infertility by Diagnostic Laproscopy
}

\author{
Tomar $\mathbf{S}^{1}$, Parmar $\mathbf{S}^{2}$, Pradhan $\mathbf{A}^{3}$ \\ ${ }^{1}$ Dr Surabhi Tomar, ${ }^{2}$ Dr Dr. Meenal Parmar, ${ }^{3}$ Dr Aritra Pradhan. All are affiliated with National Institute of Medical \\ Sciences Jaipur, Rajasthan, India.
}

Address for correspondence: Dr Surabhi Tomar, Email: surabhit@gmail.com

\begin{abstract}
Objective: To evaluate the causes of primary female infertility with diagnostic laproscopy. Study Design: This study is a case series. Place and Duration of Study: The study has been carried out in Obstetric and Gynaecology department in National Institute of Medical Sciences (NIMS) College and Hospital, Jaipur,, Rajasthan, from September 2013 to July 2014. The tubal patency was tested by chromopertubation using methylene blue dye. Methodology: Inclusion criteria include all primary infertile females who underwent diagnostic laparoscopy during the study period \& Normal pelvic examination. Couples who had not lived together for at least one year \& Women with medical disorders and contraindications for laproscopic surgery were excluded from study. Results: Out of 100 primary infertility women, mean age of infertility was 27.5 years. Maximum number of patient's presented with infertility of duration less than six years. $43 \%$ had tubal blockage as the most common finding which was followed by pelvic adhesions. Bilateral tubal block was diagnosed maximum by laproscopy and HSG combined i.e. $40 \%$ followed by laprosopy alone in 32\% cases. Conclusion: Most common causes responsible for primary infertility in women were tubal occlusion, peritubal and periovarian adhesions and endometriosis.
\end{abstract}

Key words: Laparoscopy, Primary infertility, Tubal Occlusion, Peritubal, Periovarian Adhesions.

\section{Introduction}

Approximately $5 \%$ of the couples are definitive infertile with a nearly zero chance of becoming spontaneously pregnant in the future. Fertility varies across regions of the world and is estimated to affect 8 to 12 percent of couples worldwide [1,2].Total infertility is divided into primary and secondary infertility. . For many couples, infertility and its treatment cause a serious strain on their interpersonal relationship, leading to emotional breakdowns [3]. Tube blockage is one of the most frequent causes of infertility in women.

The degree of tubal pathology determines the possibility for fertility. A number of diagnostic tests are being used in clinical practice to assess tubal patency as part of the work-up for subfertility [1]. The female factors contribute most (i.e. 40-55\%) in the etiologies of infertility followed by male factors (30-40\%), both partners $(10 \%)$ and unexplained $(10 \%)$. Infertility in female is caused by various factors.

Diagnostic laparoscopy provides a direct visual access to inner pelvic anatomy so that the ovaries, fallopian tubes and uterus can now be studied and its pathology can be directly seen in more details. The main aim of our study

Manuscript received: 30th Sept 2014,

Reviewed: 9th Oct 2014

Author Corrected: 18th Oct 2014,

Accepted for Publication: 8th Nov 2014 is to evaluate the most common pathology seen in primary infertility women with the help of laprosopy [4]. Infertility prevalence is from $3.5 \%$ to $16.7 \%$ in more developing countries,in less developed countries it is from $6.9 \%$ to $9.3 \%$ and total median prevalence is $9 \%$.In India this trend is increasing.. According to Delhi IVF Infertility Research Centre, infertility affects one in six couples. The recent National Family Health Survey (NFHS) estimates showed that, childlessness in $2.4 \%$ of currently married women aged over 40 year [5].

Pelvic inflamatory disease and Salphingitis is the common cause for tubal damages. After one episode of pelvic infection the tubal damage is $12 \%$, followed by $23 \%$ and $54 \%$ by second and third episodes respectively. The most important cause of female infertility in developing countries like India , Pakistan, Nepal, Sri lanka is Genital Tuberculosis. The diagnosis of genital tuberculosis is very tedious as false positive results supervene. It is one of the major cause of severe tubal damage. Genital tuberculosis shows varied clinical symptoms or no symptoms at all leading to its delayed diagnosis. Semen analysis has a very important role in male infertility diagnosis. If the semen analysis is abnormal, it should be repeated after at least 1 month by a laboratory that adheres to World Health Organization (WHO) guidelines, with a quality control program 
ensuring accurate testing [6]. Uterine anomalies also leads to primary infertility, Among all congenital uterine abnormalities, septate uterus is the most common cause associated with highest reproductive failure rates [7].

\section{Material and Method}

The patients were selected from the department of obstetrics and gynecology, National Institute of Medical Sciences (NIMS) College and Hospital, Jaipur, Rajasthan. The study was conducted from September 2013 to July 2014. Only selection criteria was females with one year unprotected intercourse who could not achieve pregnancy with adequate coitus, with normal bimanual pelvic examination, normal semen analysis of husband, Age group studied were of 20-40 years. Exclusion of cases were done who had abnormal semen parameters, contraindications for the surgery, related medical disorders not allowing laproscopic surgeries or unfit for surgeries. Laparoscopy was scheduled in proliferative phase of the menstrual cycle. Thorough examinations of female patients were done by initially detailed history, followed by physical examination, hormonal profiles and endocrinological examination. Full blood count, blood urea, blood sugar estimation, urine examination, ECG, Chest X ray, Ulrasonography and endometrial biopsy were performed. HSG was done as preliminary test, followed by diagnostic laparoscopy with instillation of using $10-15 \mathrm{ml}$ of $0.5 \%$ autoclaved methylene blue dye for tubal patency test. In males semen examination was done in patients selected for the study.

Methodology- Patients were enrolled after taking informed consent. Laparoscopy was performed under general anesthesia. Just below the umbilicus a small incision along the langers line made. Through that incision carbon dioxide gas insufflation done and pneumo peritoneum created. Trochar inserted through the incision and through it laparoscope is passed after withdrawing the canula. During the procedure pelvis is inspected along with the surfaces of the uterus, both the ovaries, fallopian tubes, uterosacral ligament and pouch of douglas. Fallopian tubes were inspected for abnormality in length and shape. In ovaries, their size, shape, thickness of peripheral follicle was done. Other pathologies like peritubal adhesions, omental adhesions, perifimbrial adhesions, fibroids, endometriosis, tubo ovarian mass, were also noted if present. Tubal patency was tested by injecting methylene blue dye through the uterine cavity and its spillage from the fimbrial end of the fallopian tube.

\section{Result}

Out of 100 infertile patients, the present study showed maximum cases i.e.45\% in the age group between 26-30 years followed by $35 \%$ cases in the age group of 21-25 years [table 1]

Table1: Infertility according to age group

\begin{tabular}{|c|c|c|}
\hline S NO & AGE in years & Number of cases (\%) \\
\hline 1. & $21-25$ & $35 \%$ \\
\hline 2. & $26-30$ & $45 \%$ \\
\hline 3. & $31-35$ & $20 \%$ \\
\hline
\end{tabular}

Out of 100 patients of infertility maximum cases i.e. $45 \%$ were of duration 1-5 years, followed by $6-10$ years. The least number of cases were from the duration 16-20 years [ table 2]

Table 2: Infertility duration

\begin{tabular}{|c|c|c|}
\hline S NO. & Duration of Infertility(years) & Number of cases \\
\hline 1. & $1-5$ & $45 \%$ \\
\hline 2. & $6-10$ & $35 \%$ \\
\hline 3. & $11-15$ & $12 \%$ \\
\hline 4. & $16-20$ & $8 \%$ \\
\hline
\end{tabular}

Out of 100 diagnostic laparoscopies, the most common pathology was tubal blockage with adhesions i.e. $15 \%$ or without adhesions i.e. $23 \%$. This was followed by normal pelvic findings in 30\% cases with tubal patency with adhesions in $7 \%$ cases and cystic ovaries, endometriosis with leiomyoma, hypoplastic uterus and genital tuberculosis 5\%, 5\%, 5\%, 5\% respectively [table 3] 
Table 3: Laparoscopic Findings

\begin{tabular}{|c|c|c|}
\hline S.NO. & Laparoscopy diagnosis & Cases (\%) \\
\hline 1. & Normal pelvic organs & $30 \%$ \\
\hline 2. & Tubal block with adhesions & $15 \%$ \\
\hline 3. & Tubal block without adhesions & $23 \%$ \\
\hline 4. & Tubal block with cystic ovaries & $5 \%$ \\
\hline 5. & Tubal patency with cystic ovaries & $5 \%$ \\
\hline 6. & Tubal patency with adhesions & $7 \%$ \\
\hline 7. & Genital tuberculosis & $5 \%$ \\
\hline 8. & Endometriosis with uterine leiomyoma & $5 \%$ \\
\hline 9. & Hypoplastic uterus & $5 \%$ \\
\hline
\end{tabular}

Tubal patency can be best found out by laparoscopy alone i.e. $58 \%$ cases followed by in combination of laproscopy and HSG. The bilateral block is found maximum with laparoscopy with HSG i.e. 40\%. (Table 4)

Table 4: Laparoscopic Findings

\begin{tabular}{|c|c|c|c|}
\hline S. No & Tubal patency & Laparoscopy with HSG & Laparoscopy alone \\
\hline 1. & Both Tubes patent & $50 \%$ & $58 \%$ \\
\hline 2. & Unilateral block & $10 \%$ & $10 \%$ \\
\hline 3. & Bilateral block & $40 \%$ & $32 \%$ \\
\hline
\end{tabular}

\section{Discussion}

Pelvic inflammatory disease most commonly leads to tubal blockade which is most common cause for infertility in developing countries i.e.15-20\% [2]. The study done by Kanal $\mathrm{P}$ [2] on 100 patients in India showed similar result as 70 patients had tubal blockade with or without adhesions, cystic ovaries, endometriosis, frozen pelvis, genital tuberculosis and hypoplastic uterus. The mean age in the study was 26 years. Aziz N [3] in study done on fifty infertile women, the most common cause found out was tubal blockage in 7 (21.9\%) of primary infertility. Jayakrishnan et al [4] from India detected pelvic pathology in $26.8 \%$ cases of infertile patients by laparoscopic evaluation.

The present study shows abnormal pelvic findings in $70 \%$ cases of primary infertility. The mean age of women found out to be 27.5 years. This finding is similar to that of Dhananjay Shobha [5] who studied the same in 100 patients. Founded that $50 \%$ had duration of infertility between 4 to 6 years and the mean duration was $4.62 \hat{A} \pm$ 158 years.In our study, Primary infertility was noted in $79 \%$ of the women and the mean age of primary infertility women was 28.5 years. Whether operative laparoscopy improves pregnancy outcomes in a subject with unexplained or minimal/mild endometriosis is of debate,In the intervention group 29 out of 169 got pregnant by diagnostic laproscopy in case of unexplained infertility[6] According to Boivin $\mathrm{J}$ [7] in 17 studies sampling 6410 women, the proportion of couples seeking medical care was, on average, $56.1 \%$ (range $42-76.3 \%$ ) in more developed countries and $51.2 \%$ (range 27$74.1 \%$ ) in less developed countries. The proportion of people actually receiving care was substantially less, $22.4 \%$. Based on these estimates and on the current world population, 72.4 million women are currently infertile; of these, 40.5 million are currently seeking infertility medical care. Nayak PK [8] studied 300 infertile patients in which, 69\% women had primary infertility and the laproscopic abnormalities were more common in primary infertility group i.e. $35 \%$. In our study, maximum number of patients $(46.67 \%)$ presented with less than 6 years of infertility, this was consistent with the finding of Shetty SK [9] wherein 1-5 years of infertility duration, there were $64 \%$ of the women whereas $34 \%$ of the women had infertility of duration 6-10 years.

The most common age group was between 21-35 years with $88 \%$. The tubal pathology was detected in $64.7 \%$ cases of primary infertility.In our study, the most common cause of infertility i.e. $43 \%$ was tubal blockage with adhesions, without adhesions and with cystic ovaries. Bilateral block is more found out by laproscopy and HSG combined which is $40 \%$ whereas by laproscopy alone, it is 32. Study done by Samal S [10] found that tubal causes (peritubal adhesions, tubalblockage, tubo ovarian masses and hydrosalpinx) contributed about 34 (34\%) cases, among which 28 cases $(37.33 \%)$ were of primary infertility. The gold standard technique for diagnosing these disorders is laparoscopy. This can be used for couples with unexplained infertility.

Available online at: www.ijmrr.in 563 | P a g e 


\section{Conclusion}

The most common abnormality detected in primary infertility patients is tubal blockage with or without adhesions. Laparoscopy along with HSG is very effective method in evaluating cases of primary infertility especially tubal blockage. HSG and Laparoscopy should be considered as complimentary procedures rather that competitive procedure.

When both of these diagnostic modalities are combined, gives the best result, in cases if anyone shows doubtful result. In the days of modern gynecology, where alternative modalities like salpingoscopy, falloscopy and hysteroscopy are available for assessment of tubal patency, but laproscopy is still the gold standard for diagnosis of infertility causes.peritubal and peri fimbrial adhesions are factors resposible for defective ovum pick up and transport.

Further studies are needed to investigate the etiologies of these abnormalities at the earliest as this could be a measure to bring down the occurrence of such conditions. Infertility affects approximately $10 \%$ of the population, one third to male , one third to female infertility and $10 \%$ are combined factors. In about $20 \%$ cases on fertility cause is unexplained. It becomes very essential to find out the main cause of infertility as long term infertility becomes tedious to treat.

Funding: Nil Conflict of interest: Nil Permission from IRB: Yes

\section{References}

1. Foroozanfard F, Sadat Z, Diagnostic Value of Hysterosalpingography and Laparoscopy for Tubal Patency in Infertile Women Nurs Midwifery Stud. 2013 Jun;2(2):188-192. Epub 2013 Jun 27. [PubMed]

2. Kanal P, Sharma S. Study of Primary Infertility in females by Diagnostic Laproscopy. Internet Journal of Medical Update 2006 Jul-Dec;1(2):7-9.
3. Aziz N, .Role of Diagnostic Laproscopy in primary and secondary Infertility. Journal of the College of Physicians and Surgeons Pakistan 2010, Vol. 20 (10): 649-652. [PubMed]

4. Jayakrishnan K, Koshy AK, Raju R. Role of laparohysteroscopy in women with normal pelvic imaging and failed ovulation stimulation with intrauterine insemination. J Hum Reprod Sci 2010;3(1): 20-4.[PubMed]

5. Dhananjaya S, K. N. Madhu, Agrawal Amiti. Role of Diagnostic Hysterolaparoscopy in Evaluation of Primary and Secondary Infertility. Journal of Evolution of Medical and Dental Sciences 2014; Vol. 3, Issue 09, March 3; Page: 2194-2207, DOI: 10.14260/jemds/2014/ 212.

6. Dokras A, Quass A Diagnosis and Treatment of Unexplained Infertility Rev Obstet Gynecol. 2008 Spring; 1(2): 69-76. [PubMed]

7. Boivin J, Bunting L, Collins JA, Nygren KG. International estimates of infertility prevalence and treatment-seeking: Potential need and demand for infertility medical care. Hum Reprod. 2007 Jun;22(6): 1506-12. Epub 2007 Mar 21. [PubMed]

8. Nayak PK, MahapatraCP,Role of diagnostic hysterolaparoscopy in the evaluation of infertility: A retrospective study of 300 patients. J Hum Reprod Sci. 2013 Jan-Mar; 6(1): 32-34. [PubMed].

9. Shraddha K. Shetty, Harish Shetty, Supriya Rai. Laparoscopic evaluation of tubal factor in cases of infertility. Int J Reprod Contracept Obstet Gynecol 2013 sep;2(3):410-413.

10. Samal S, Agrawal S, Agrawal M. Role of laparoscopy in infertility in a rural setup hospital. Int $\mathrm{J}$ Reprod Contracept Obstet Gynecol. 2014; 3(1): 185-188. doi:10.5455/2320-1770.ijrog20140337.

\section{How to cite this article?}

Tomar S, Parmar S, Pradhan A. Causes of female infertility by Diagnostic Laproscopy. Int J Med Res Rev 2014;2(6): 561-564. doi:10.17511/ijmrr.2014.i06.09 